\title{
Ventilation and Oxygen: Dose-Related Effects of Oxygen on Ventilation-Induced Lung Injury
}

\author{
BETH J. ALLISON, KELLY J. CROSSLEY, SHARON J. FLECKNOE, PETER G. DAVIS, COLIN J. MORLEY, \\ AND STUART B. HOOPER \\ Department of Physiology [B.J.A., K.J.C., S.J.F., S.B.H.], Monash University, Monash, Victoria 3800, Australia; Neonatal Research \\ [P.G.D., C.J.M.], Royal Women's Hospital, Parkville, Victoria 3052, Australia
}

\begin{abstract}
Preterm infants are at high risk of developing ventilator-induced lung injury. We have used an animal model of in utero ventilation (IUV) to investigate the separate effects of ventilation and acute oxygen exposure on the very immature lung. Fetal sheep were ventilated in utero at $110 \mathrm{~d}$ gestation for $6 \mathrm{~h}$ with 100, 21, or $0 \%$ (100\% nitrogen) oxygen ( $n=5$ each) and survived in utero, without further ventilation, until tissue collection at $118 \mathrm{~d}$. Nonventilated $110 \mathrm{~d}$ and $118 \mathrm{~d}$ fetuses were used as controls. All IUV exposed fetuses had reduced secondary septal crest densities and increased elastin staining irrespective of the inspired oxygen concentration. IUV with $100 \%$ and $21 \%$ oxygen, but not $100 \%$ nitrogen, increased lung tissue volumes and myofibroblast differentiation and apoptosis within the distal lung parenchyma in a dose-dependent manner. This study shows that IUV without oxygen can reduce alveolarization, whereas ventilation with oxygen $(6 \mathrm{~h})$, even at levels found in air $(21 \%)$, increases distal lung tissue volumes, elastin deposition, myofibroblast differentiation, and apoptosis. (Pediatr Res 67: 238-243, 2010)
\end{abstract}

$\mathrm{V}$ ery preterm infants commonly require respiratory support after birth but debate exists as to the appropriate levels of inspired oxygen $\left(\mathrm{FiO}_{2}\right)$. As very preterm infants have an immature antioxidant system, they are susceptible to oxidative damage on exposure to high $\mathrm{FiO}_{2}$ levels (1). Although high $\mathrm{FiO}_{2}$ levels are often required to sustain appropriate oxygenation levels in very preterm infants, it is one of the greatest risk factors predisposing infants to bronchopulmonary dysplasia (BPD) (2). Indeed, prolonged exposure of immature lungs to hyperoxia can reproduce many structural changes that are characteristic of BPD (3-5). As high $\mathrm{FiO}_{2}$ levels are often given with respiratory support, it is difficult to assess the relative contributions of these factors to neonatal lung injury $(6,7)$.

Models of hyperoxia-induced lung injury in newborns exist in many species $(2,3,8,9)$. These studies show that chronic hyperoxia causes pathologic changes in lung structure, including inhibiting DNA synthesis, arresting alveolarization (812 ), and remodeling of the pulmonary microvasculature thus

Received September 15, 2009; accepted November 10, 2009.

Correspondence: Beth Allison, Ph.D., Department of Physiology, Monash University, Monash, Victoria 3800, Australia; e-mail: beth.allison@med.monash.edu.au

Supported by grants from the Australian NHMRC and Monash University. increasing susceptibility of the newborn to pulmonary hypertension $(2,13,14)$. Although mechanical ventilation can cause lung injury in the absence of high levels of oxygen $(15,16)$, and the combined effect of ventilation and hyperoxia cause BPD-like alterations in lung morphology, hyperoxia is thought to have greater effects on lung pathology than ventilation per se (2). This implies a causative role for oxygen in the etiology of BPD, but the specific pathologic changes caused by oxygen are not clear. Furthermore, although, it is well established that chronic hyperoxia causes lung injury $(8,17)$, little is known about the consequences of an acute exposure $(<6 \mathrm{~h})$ for very preterm infants. Indeed, many preterm infants are exposed to high $\mathrm{FiO}_{2}$ levels for only a short period; particularly during the immediate newborn period. The relative contribution of oxygen on structural changes associated with BPD is not clear, nor is whether room air (21\%) is injurious to very immature lungs.

Our aim was to use our model of in utero ventilation (IUV), described previously (18), to investigate the independent effects of inspired oxygen and mechanical ventilation on abnormal lung development in the very immature lung, using i) high $(100 \%)$, ii) normal (room air, $21 \%$ ), and iii) zero (ventilation with $100 \%$ nitrogen) oxygen levels. Because pulmonary gas exchange is not required to maintain fetal homeostasis, the fetus can be ventilated with any $\mathrm{FiO}_{2}$ (even 0\% oxygen) without adverse consequences. The maintenance of placental support also allows the fetus remains in utero, following the cessation of ventilation, allowing time $(7 \mathrm{~d})$ for pathologic changes in lung structure to manifest without any adverse influences from prolonged respiratory and nutritional support. Specifically, we hypothesized that ventilation in the absence of oxygen will disrupt lung development and that a brief $(6 \mathrm{~h})$ exposure to both 21 and $100 \%$ oxygen will exacerbate the changes in lung structure.

Abbreviations: $\mathbf{2 1 \%} \mathbf{O}_{2}, 6 \mathrm{~h}$ of in utero ventilation with $21 \%$ oxygen; $\mathbf{1 0 0 \%}$ $\mathbf{N}_{2}, 6 \mathrm{~h}$ of in utero ventilation with $100 \%$ nitrogen; $\mathbf{1 0 0 \%} \mathbf{O}_{2}, 6 \mathrm{~h}$ of in utero ventilation with $100 \%$ oxygen; $\boldsymbol{\alpha S M A}$, alpha-smooth muscle actin; BPD, Bronchopulmonary Dysplasia; $\mathbf{F i O}_{2}$, Fraction of inspired oxygen; IUV, In utero ventilation; VILI, Ventilation-induced lung injury 


\section{MATERIALS AND METHODS}

Fetal surgery. All experimental procedures were approved by the Monash University Animal Ethics Committee. Aseptic surgery was performed on thirty Border-Leicester $\times$ Merino ewes at 105-d gestation (term is $\sim 147 \mathrm{~d}$ ). Anesthesia was induced via an i.v. bolus of 5\% sodium thiopentone (Pentothal; $1 \mathrm{~g}$ in $20 \mathrm{~mL}$ ) and was maintained, after intubation, with inhalation of $1.5-3 \%$ halothane in $\mathrm{O}_{2}$. During surgery, an endotracheal tube was inserted into the fetal trachea and connected, via a Y-piece, to two large bore, saline-filled, ventilation tubes (ID $9.5 \mathrm{~mm}$ and OD $14.3 \mathrm{~mm}$ ). A saline-filled catheter (ID $3.2 \mathrm{~mm}$ and OD $6.4 \mathrm{~mm}$ ) was inserted into the upper fetal trachea and connected to a saline-filled ventilation tube to create an exteriorized fetal tracheal loop, allowing the normal flow of fetal lung liquid (Fig. 1). Polyvinyl catheters were implanted into the fetal carotid artery, jugular vein, and amniotic sac and exteriorized via the ewe's flank. Ewes and fetuses were allowed $5 \mathrm{~d}$ recovery in air after surgery. Fetal arterial blood $\mathrm{PaO}_{2}, \mathrm{PaCO}_{2}$, $\mathrm{pH}$, and $\mathrm{SaO}_{2}$ were measured every second day to assess fetal wellbeing.

Experimental protocol. Before IUV, ventilation tubes were disconnected from the upper tracheal catheter and the liquid drained into a sterile bag before the tubes were connected to a neonatal ventilator (Draeger $8000+$ ). Fetuses were divided into three groups $(n=5$ each), which received ventilation with 1) $\mathrm{FiO}_{2}$ of $1.0\left(100 \% \mathrm{O}_{2}\right)$, 2) air $\left(\mathrm{FiO}_{2} 0.2 ; 21 \% \mathrm{O}_{2}\right)$, or 3) $100 \%$ nitrogen $\left(\mathrm{FiO}_{2} 0 ; 100 \% \mathrm{~N}_{2}\right)$. Two additional groups acted as age-matched (either $110 \mathrm{~d}$ or $118 \mathrm{~d}$ ) nonventilated controls. In groups $1-3$, fetuses were ventilated in utero for $6 \mathrm{~h}$ at 110-d gestation using a peak inspiratory pressure of 35 $\mathrm{cmH}_{2} \mathrm{O}$, a positive end-expiratory pressure of $6 \mathrm{cmH}_{2} \mathrm{O}$, an inspiratory flow of $15 \mathrm{~L} / \mathrm{min}$, and a rate of 65 inflations $/ \mathrm{min}$.

Arterial and amniotic sac pressures were measured using pressure transducers and recorded digitally (Powerlab, ADIinstruments, Australia). Arterial blood gases were measured hourly. After ventilation, fetal lung liquid was replaced, and the upper tracheal catheter was reconnected to restore normal lung liquid flow. Ewes and fetuses were killed with anesthetic overdose (sodium pentobarbitone; $130 \mathrm{mg} / \mathrm{kg}$ i.v.) $7 \mathrm{~d}$ after IUV (118 d GA).

Tissue collection. The fetal lungs were drained of liquid, weighed, the left bronchus ligated, and portions of the left lung snap frozen and stored at $-70^{\circ} \mathrm{C}$. The right lung was fixed at $20 \mathrm{cmH}_{2} \mathrm{O}$ via the trachea with $4 \%$ paraformaldehyde, postfixed in Zamboni's fixative, and processed for light microscopy; $20 \mathrm{cmH}_{2} \mathrm{O}$ inflates the fetal lungs to a luminal volume similar to that observed in vivo (19). Percentage water content of lung tissue was determined by drying known weight tissue samples, in a $70^{\circ} \mathrm{C}$ oven until no change in weight was detected for 3 consecutive days. The difference between wet and dry tissues weight was used to calculate water content.

Histologic analysis of lung tissue injury. The right lung was separated into cranial, middle, and caudal lobes and cut into $5 \mathrm{~mm}$ slices. Every second slice, from each lobe, was divided into three. Six pieces were chosen at random (using a random number table) from each lobe, cut into $2 \mathrm{~cm}^{2}$ sections (5-mm thick) and embedded in paraffin. Blocks were randomly selected from each lobe and sectioned at $5 \mu \mathrm{m}$; sections were incubated at $60^{\circ} \mathrm{C}(2 \mathrm{~h})$, deparaffinized, rehydrated, and washed in PBS.

Different sections were stained with hematoxylin and eosin, Hart's resorcin-fuschin (elastin), and Gordon and Sweets reticulum (collagen). Immuno-

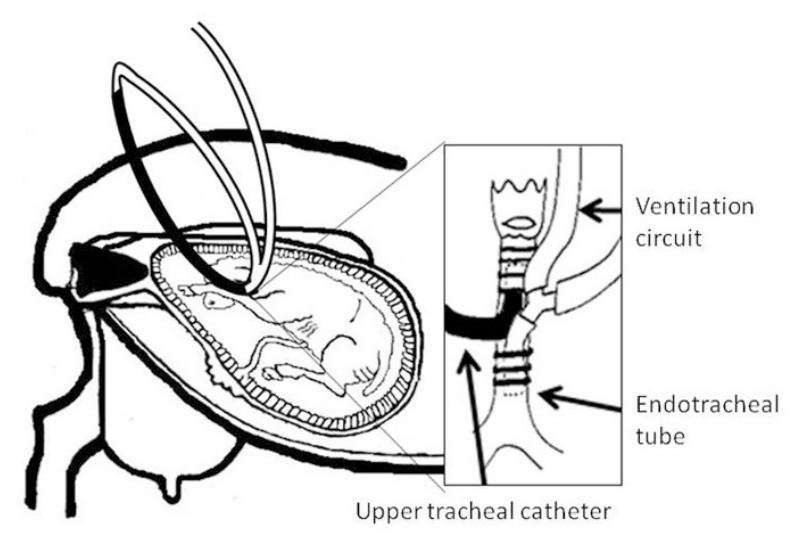

Figure 1. Setup of tracheal loop. The ventilation tubes (white) were connected to the endotracheal tube, directed toward the lung, via a "Y" piece. An upper trachea catheter (black) was also inserted and directed toward the glottis, and after surgery, this was connected to one of the ventilating tubes to allow normal flow of lung liquid. histochemistry was used to identify differentiated myofibroblasts (alpha smooth muscle actin, $\alpha \mathrm{SMA}$ ). The percentage of space occupied by lung tissue was measured by image analysis, validated using a point counting technique (20), whereas secondary septal crest densities were measured using a point-counting technique and expressed in relation to tissue area; five sections and three fields of view per section were used for these analyses. Elastin, collagen, and $\alpha$ SMA staining density was measured by image analysis (ImagePro plus) using five random fields of view per section of the lung; assessed by single observer (BJA) blinded to the experimental group. For each field of view, staining density was adjusted for tissue area.

Immunohistochemistry. Tissue sections were boiled in sodium citrate $(0.01 \mathrm{M}, \mathrm{pH} 6.0)$, washed in PBS $(2 \times 5 \mathrm{~min})$, and incubated in hydrogen peroxide $(3 \%, 5 \mathrm{~min})$. The sections were rinsed in water, washed in PBS, and incubated in blocking/permeabilization buffer (3\% normal goat serum; 0.1\% TritonX-100 in PBS). Sections were incubated with primary antibody (antihuman $\alpha$ SMA; Dakocytomation, Denmark) for $90 \mathrm{~min}$ (RT), washed in PBS (with $0.1 \%$ Tween-20) for $5 \mathrm{~min}(3 \times)$, and incubated with biotinylated secondary antibody (anti-mouse Biotinylated $\mathrm{Ab}$; Vector laboratories, Burlingame, CA) in PBS for $1 \mathrm{~h}$. Sections were again washed in PBS/0.1\% Tween-20 for $5 \mathrm{~min}(3 \times)$ and the biotinylated secondary antibody detected (Vectastain ABC kit, PK-6100 Standard; Vector laboratories). Sections were washed, dehydrated, mounted, and viewed using light microscopy.

Statistical analysis. Values are expressed as mean \pm SEM. Statistical comparisons between treatments in histologic observations were made with a nested ANOVA; significance between individual values was determined using a LSD post hoc test.

\section{RESULTS}

Fetal arterial blood gas status. All fetuses had normal blood gas and acid-base status throughout these experiments. Fetal blood gases did not change from pre-experimental values $\left(\mathrm{PaO}_{2} 21.4 \pm 1.7 \mathrm{~mm} \mathrm{Hg}, \mathrm{PaCO}_{2} 51.3 \pm 5 \mathrm{~mm} \mathrm{Hg}, \mathrm{SaO}_{2}\right.$ $67.9 \pm 6 \%$, and $\mathrm{pH} 7.361 \pm 0.01)$ throughout the IUV period and were similar to unventilated controls fetuses at the same gestational age (data not shown).

General morphology. At $110 \mathrm{~d}$ GA, control fetuses have thick interstitial tissue separating future airspaces and some immature secondary septal crests were detected (Fig. $2 C, a$ ). At $118 \mathrm{~d}$, the interalveolar septa of control fetal lungs had significantly thinned, compared with $110 \mathrm{~d}$ control fetuses, and the relative density of secondary septal crests had markedly increased (Fig. 2C, b). Fetuses ventilated with both $21 \%$ (Fig. 2C, $d$ ) and $100 \% \mathrm{O}_{2}$ (Fig. 2C, c) had interalveolar septa that were significantly thicker than $118 \mathrm{~d}$ age-matched controls and were similar to the $110 \mathrm{~d}$ controls. In contrast, fetuses ventilated with $100 \%$ nitrogen (Fig. $2 C, e$ ) had similar interalveolar septa that were of similar thickness as $118 \mathrm{~d}$ unventilated controls.

The percentage of total lung space occupied by tissue (Fig. $2 A$ ) within the saccular/alveolar region of the lung was significantly lower in $118 \mathrm{~d}(32.5 \pm 2.4 \% ; p<0.05)$ controls compared with $110 \mathrm{~d}$ controls $(49.8 \pm 2.2 \%)$, in-line with normal lung maturation. Compared with nonventilated $118 \mathrm{~d}$ age-matched controls, the percentage of space occupied by lung tissue was significantly increased $(p<0.05)$ in fetuses ventilated with $21 \% \mathrm{O}_{2}(45.4 \pm 3.3 \%)$ and $100 \% \mathrm{O}_{2}(47.2 \pm$ $5.1 \%)$. However, in fetuses ventilated with $100 \%$ nitrogen, the percentage of space occupied by lung tissue $(35.8 \pm 5.6 \%)$ was not different to nonventilated $118 \mathrm{~d}$ controls.

Secondary septal crest densities. In control fetuses, the density of secondary septal crests significantly increased $(p<$ 0.01 ) from $6.8 \pm 1.3 \%$ of lung tissue at $110 \mathrm{~d}$ to $11.1 \pm 0.6 \%$ of lung tissue at $118 \mathrm{~d}$ (Fig. 2C). Compared with $118 \mathrm{~d}$ age-matched controls, secondary septal densities were signif- 

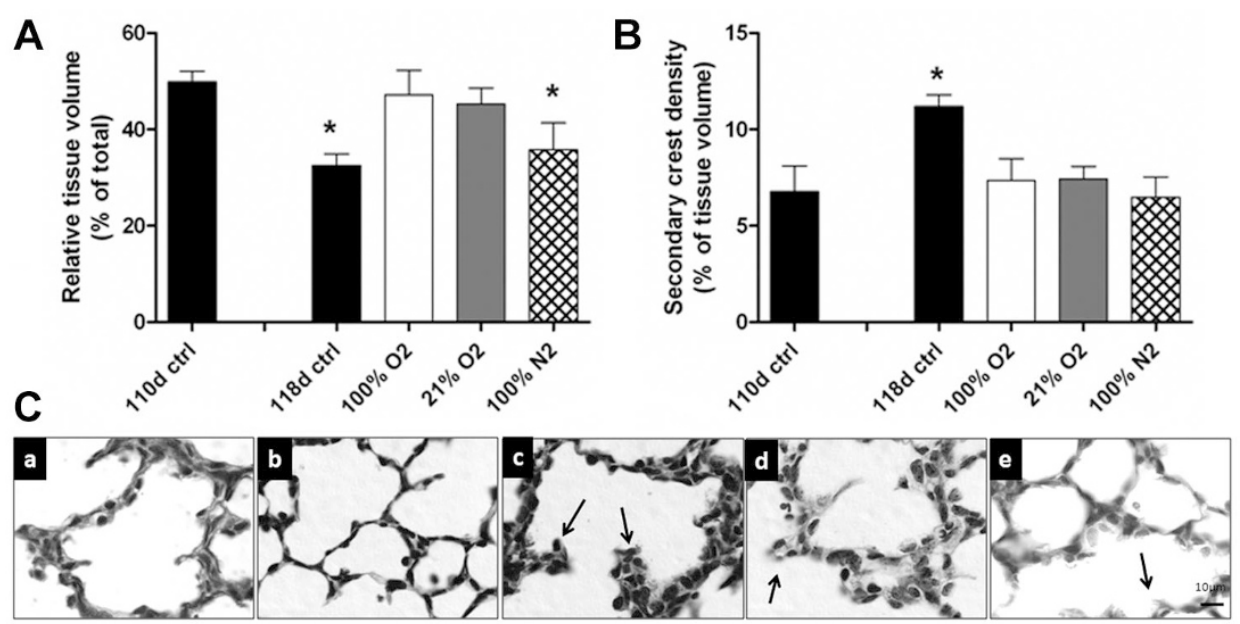

Figure 2. (A) Relative tissue volume (\% of total) and $(B)$ secondary septal crests density in $110 \mathrm{~d}(n=5)$ and $118 \mathrm{~d}(n=4)$ controls and in fetuses ventilated in utero with either $100 \%$ or $21 \%$ (air) oxygen or $100 \%$ nitrogen $(n=5$ each). Asterisks indicate significant difference from all other groups $(p<0.05)$. $(C)$ Tissue stained with hematoxylin and eosin and photographed at high $(1000 \times)$ magnification. Between $110 \mathrm{~d}$ GA $(a)$ and $118 \mathrm{~d}$ GA $(b)$, interalveolar septa are thinning and secondary septal crest development commences. IUV with either $100 \%(c)$ or $21 \%(d)$ oxygen prevented the normal GA-related decrease in interalveolar septal wall thickness whereas IUV without oxygen (100\% nitrogen); (e) had no effect on interalveolar septal wall thinning. Secondary crests appeared altered in ventilated fetuses (arrows). Scale bar $=10 \mu \mathrm{m}$.

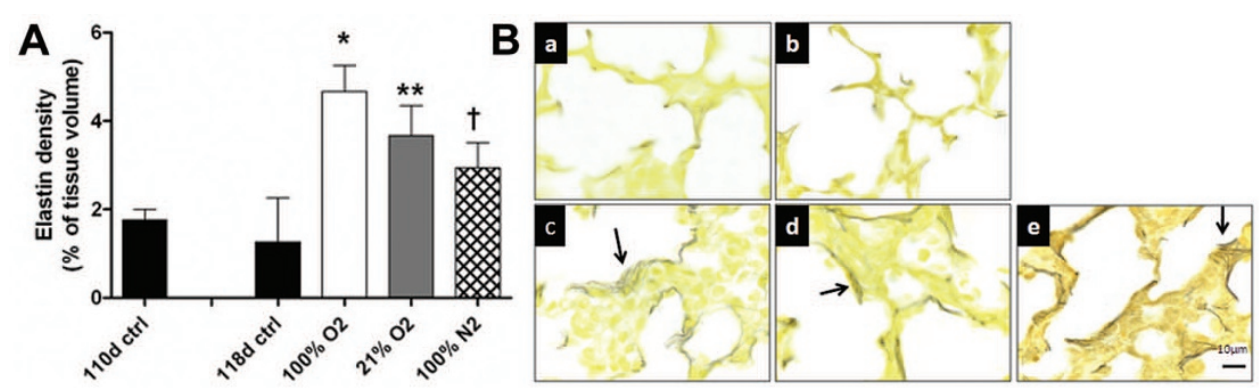

Figure 3. (A) Elastin staining density (\% of tissue area) in $110 \mathrm{~d}$ and $118 \mathrm{~d}$ controls (black bars) and in fetuses ventilated in utero with either $100 \%$ (white bar) or $21 \%$ (gray bar) oxygen or $100 \%$ nitrogen (hatched bar). Groups that do not share a common symbol are significantly different from each other $(p<0.01)$. (B) Elastin (stained dark) fibers in the distal lung of $110 \mathrm{~d}(a ; n=5)$ and $118 \mathrm{~d}(b ; n=4)$ controls and fetuses ventilated in utero with either $100 \%(c ; n=$ 5 ) or $21 \%$ (air; $d ; n=5$ ) oxygen or $100 \%$ nitrogen $(e ; n=5$ ). Abnormal deposition of elastin was observed after ventilation (arrows). Magnification $\times 1000$; Bar $=10 \mu \mathrm{m}$.

icantly reduced in fetuses ventilated with both $21 \% \mathrm{O}_{2}(7.4 \pm$ $0.6 \%)$ and $100 \% \mathrm{O}_{2}(7.3 \pm 1.1 \%)$. Similarly, in fetuses ventilated with $100 \%$ nitrogen, secondary septal crest densities $(6.5 \pm 1.1 \%)$ were significantly reduced compared with $118 \mathrm{~d}$ controls and were not different to $110 \mathrm{~d}$ controls. Furthermore, in each of the ventilated fetuses, the secondary septal crests appeared thicker and shorter compared with age-matched controls (Fig. $2 C$, c-e arrows).

Elastin. Elastin density in peri-saccular/alveolar regions was similar in controls at both ages $(110 \mathrm{~d} 1.8 \pm 0.2 \%$ versus 118 d $1.3 \pm 0.9 \%$; Fig. $3 A$ ). In all IUV fetuses, ventilation significantly increased elastin density $(p<0.01)$ in a dosedependent manner, with $100 \% \mathrm{O}_{2}$ exposed fetuses having the largest increase and $100 \% \mathrm{~N}_{2}$ exposed fetuses having the smallest increase $\left(100 \% \mathrm{O}_{2}, 4.7 \pm 0.6 \% ; 21 \% \mathrm{O}_{2}, 3.7 \pm\right.$ $0.7 \%$; and $100 \% \mathrm{~N}_{2}, 2.9 \pm 0.6 \%$; Fig. 5A). In $110 \mathrm{~d}$ and $118 \mathrm{~d}$ control fetuses (Fig. $3 B, a$ and $b$ respectively), elastin deposition occurred predominantly at tips of developing secondary septa, although some staining also occurred in saccule walls. In all fetuses, IUV increased elastin staining around the base of saccule walls, with increased staining of fine mesh-like fibers throughout the interalveolar septa (Fig. 3B, $c-e$ arrows) and staining was less prominent in secondary septal crests, particularly as there were fewer crests.

Collagen. The density of collagen staining was significantly greater $(p<0.01)$ in $118 \mathrm{~d}(23.2 \pm 3.4 \%)$ compared with $110 \mathrm{~d}(20.5 \pm 0.7 \%)$ controls (Fig. 4A). There was no difference in the density of collagen in fetuses ventilated with both $21 \%(24 \pm 2.7 \%)$ and $100 \% \mathrm{O}_{2}(25.2 \pm 1.6 \%)$ and controls but not with $100 \% \mathrm{~N}_{2}(10 \pm 0.8 \%$, Fig. $4 A)$. Although it is barely visible, in control fetuses, a fine mesh-like structure surrounds the saccule walls and interconnects with a thicker collagen fiber network that projects between saccules (Fig. $4 B, a$ and $b$ ). In ventilated fetuses, this fine mesh-like structure is thicker and the collagen structure appeared more torturous and disorganised (Fig. $4 B, c-e$ ).

Myofibroblast differentiation. In control fetuses, $\alpha$ SMA staining, as a proportion of lung tissue, was significantly ( $p<$ 0.01 ) reduced from $18.6 \pm 3.5 \%$ at $110 \mathrm{~d}$ to $13.6 \pm 1.5 \%$ at $118 \mathrm{~d}$, which was not significantly different to fetuses ventilated with $100 \%$ nitrogen $(10.6 \pm 4.5 \%)$. However, ventilation with $21 \%$ oxygen significantly increased $\alpha$ SMA staining 


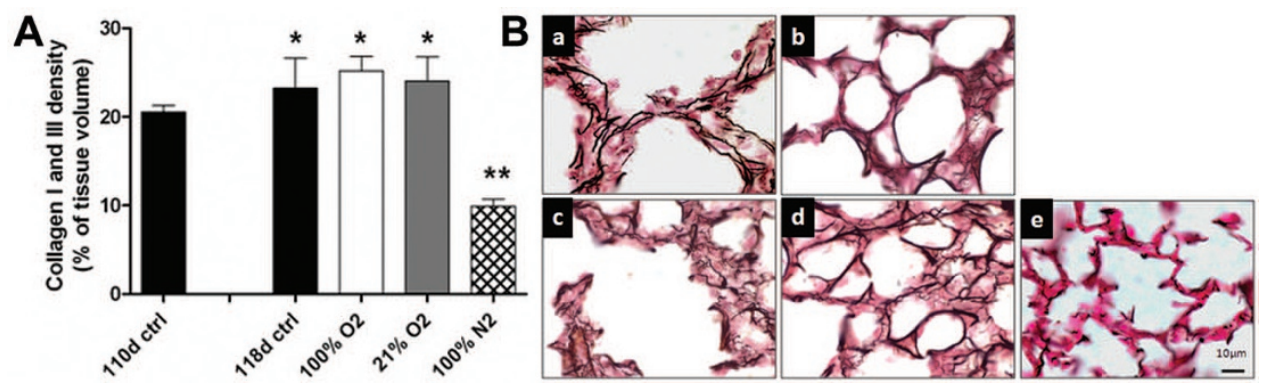

Figure 4. (A) Collagen staining density (\% of lung tissue area) in $110 \mathrm{~d}$ and $118 \mathrm{~d}$ controls (black bars) and in fetuses ventilated in utero with either $100 \%$ (white bar) or $21 \%$ (gray bar) oxygen or 100\% nitrogen (hatched bar). Groups that do not share a common symbol are significantly different from each other $(p<0.01$ ). (B) Collagen (stained black) fibers in distal lung tissue of $110 \mathrm{~d}(a ; n=5)$ and $118 \mathrm{~d}(b ; n=4)$ control fetuses and in fetuses ventilated in utero with either $100 \%(c ; n=5)$ or $21 \%$ (air; $d ; n=5$ ) oxygen or $100 \%$ nitrogen $(e ; n=5)$. Magnification $\times 1000$; Bar $=10 \mu \mathrm{m}$.

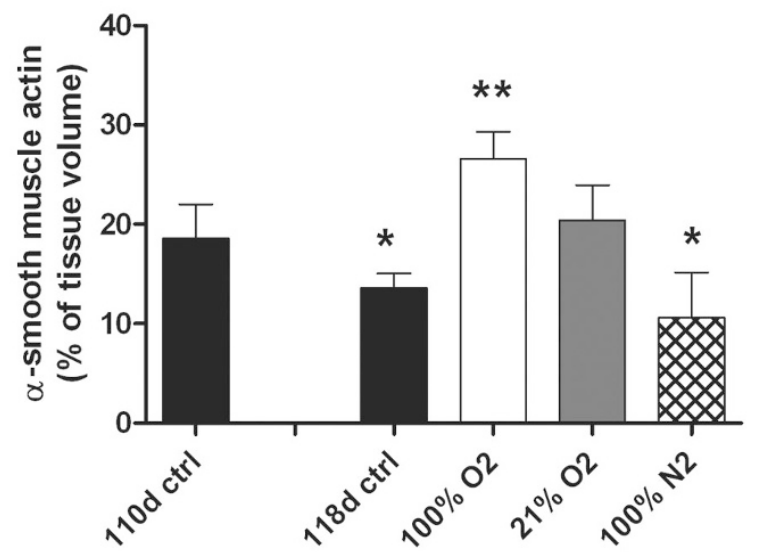

Figure 5. Alpha smooth muscle actin ( $\alpha$ SMA) staining density (\% of lung tissue area) in $110 \mathrm{~d}$ and $118 \mathrm{~d}$ controls (black bars) and in fetuses ventilated in utero with either $100 \%$ (white bar) or $21 \%$ (gray bar) oxygen or $100 \%$ nitrogen (hatched bar). Groups that do not share a common symbol are significantly different from each other $(p<0.05)$.

(to $20.4 \pm 3.5 \% ; p<0.05$ ) compared with age-matched controls (118 d), and staining was increased further (to $26.6 \pm$ $2.8 \% ; p<0.01$ ) in fetuses ventilated with $100 \% \mathrm{O}_{2}$ (Fig. 5). In control fetuses, $\alpha$ SMA staining was localized to the tips of developing secondary septal crests and around airways. In fetuses exposed to IUV with either $21 \% \mathrm{O}_{2}$ or $100 \%$ nitrogen, myofibroblast staining remained primarily at tips of developing secondary septal crests and surrounding developing airways. In contrast, IUV with $100 \% \mathrm{O}_{2}$ increased myofibroblast staining with dense deposits around individual nuclei of developing airways as well as intermittent staining seen throughout the interstitium.

Caspase-3 positive cells. The percentage of cells staining positively for caspase-3, a marker for apoptosis significantly decreased $(p<0.01)$ in controls between $110 \mathrm{~d}(18.7 \pm 6 \%)$ and $118 \mathrm{~d}(4.6 \pm 1.9 \%)$ gestation. Ventilating fetuses with $21 \%$ or $100 \% \mathrm{O}_{2}$ significantly increased the percentage of caspase-3 positive cells $(13.7 \pm 4.1 \%$ and $15.9 \pm 3.6 \%$, respectively) compared with $118 \mathrm{~d}$ age-matched controls and were not different to the percentage of caspase-3 positive cells in $110 \mathrm{~d}$ controls. In contrast, the percentage of caspase- 3 positive cells was not significantly different in $118 \mathrm{~d}$ unventilated controls and fetuses ventilated with $100 \%$ nitrogen (Fig. 6). Positively staining cells appeared to be mainly interstitial cells in ventilated fetuses.

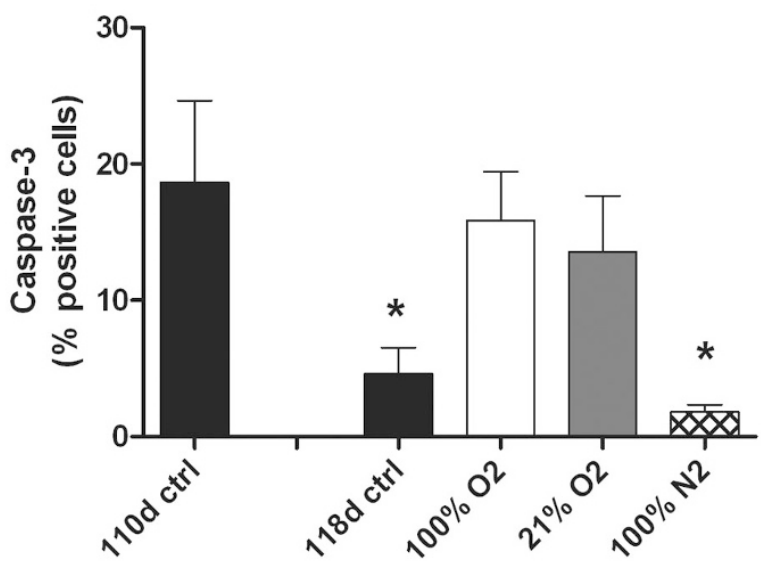

Figure 6. Caspase-3 staining density (\% of lung tissue area) in $110 \mathrm{~d}$ and $118 \mathrm{~d}$ controls (black bars) and in fetuses ventilated in utero with either $100 \%$ (white bar) or 21\% (gray bar) oxygen or 100\% nitrogen (hatched bar). Groups that do not share a common symbol are significantly different from each other $(p<0.05)$.

\section{DISCUSSION}

This study demonstrates, for the first time, that oxygen and ventilation may contribute separately to alterations in immature lung structure after ventilation-induced lung injury (VILI). Irrespective of the level of inspired oxygen $(0,21$, or $100 \%$ ), ventilation reduced alveolar formation, as indicated by decreased secondary crest densities and abnormal elastin deposition. The addition of oxygen during ventilation, irrespective of its level (100\% or $21 \%$ ), caused marked changes distal lung tissue. These were indicated by increased perialveolar tissue volumes and perialveolar myofibroblast differentiation, altered collagen deposition, and increased indices of apoptosis. Exposure to hyperoxia $\left(100 \% \mathrm{O}_{2}\right)$ further increased both elastin deposition and myofibroblast differentiation, compared with $21 \% \mathrm{O}_{2}$, although there was no further increase in apoptosis or perialveolar tissue volumes. These experiments provide further evidence that the abnormal lung development caused by ventilation is multifactorial.

Our goal was to ventilate as gently as possible, using pressures (PIP $35 \mathrm{cmH}_{2} \mathrm{O}$, PEEP $6 \mathrm{cmH}_{2} \mathrm{O}$ ) known to aerate the lung (tidal volumes $<5 \mathrm{~mL} / \mathrm{kg}$ in this model, (18). However, ventilation consistently decreased secondary septal crest density and increased elastin deposition irrespective of the gas mixture used. Furthermore, secondary septal crests appeared 
thicker and shorter in comparison to nonventilated controls, as has been previously observed $(18,21)$. These data indicate that mechanical ventilation alone adversely affects septal crest formation and that an acute $(6 \mathrm{~h})$ exposure to oxygen has no further effect, even when increased to $100 \%$. Although, this finding is not consistent with previous studies $(8,10,22-25)$, which showed that hyperoxia decreased secondary crest densities relative to air, the exposure to hyperoxia was much shorter in our study. In our previous study (18), we found that IUV using a higher PIP, markedly reduced septal crest densities even in fetuses examined only $12 \mathrm{~h}$ after ventilation onset. We suggested the mechanical effect of ventilation may have destroyed immature secondary septal crests causing them to flatten and rejoin the saccular wall (18). This suggestion was consistent with an increased elastin distribution within the primary saccule walls. Our finding that ventilation with $100 \% \mathrm{~N}_{2}$ reduces secondary septal crest densities in the absence of oxygen further supports our contention that the inhibitory effect ventilation on alveolar formation is predominantly mechanical.

IUV increased elastin density and altered its spatial pattern of deposition within the distal lung parenchyma, causing increased fiber deposition within the primary saccule walls. These changes are consistent with previous studies following both VILI $(18,21,26,27)$ and hyperoxia $(28,29)$, which showed an increase in elastin fiber thickness (28). We found that although $100 \% \mathrm{~N}_{2}$ significantly increased elastin deposition, relative to age matched controls, oxygen significantly increased elastin deposition further in a dose-dependent manner. How oxygen may induce this effect is unknown, previous studies have shown prolonged hyperoxia to inhibit tropoelastin gene expression and increase elastin degradation (30-32). However, the effect of acute hyperoxia on tropoelastin gene expression and elastin degradation is unknown.

Exposure to any period of oxygen concentration significantly altered lung structure, as indicated by an increase in distal airway tissue volumes, and may have caused long-term changes in cell populations within the distal lung parenchyma. This is indicated by an increase in $\alpha$ SMA staining, which is a cell marker for differentiated myofibroblasts in the distal lung parenchyma (33) and an increase in apoptosis. Controlled transdifferentiation of immature lipofibroblasts into myofibroblasts is an important developmental process that regulates structural development of the distal gas exchange structures (34). Myofibroblasts synthesize and deposit collagen and elastin in the perialveolar region of the lung (35) and are involved in the outgrowth of secondary septal crests (34). However, excessive transdifferentiation into myofibroblasts occurs in response to injury and is associated with $\operatorname{BPD}(22,30,35)$. It is suggested that an inability of immature fibroblasts to retain their lipofibroblast characteristics (i.e., not transdifferentiate into myofibroblasts) contributes to VILI in preterm infants (36). Increased myofibroblasts numbers could result in increased extracellular matrix deposition, fibrosis (30), and dysregulation of the normal developmental program leading to abnormal development. Increased myofibroblast differentiation may explain the increased collagen and elastin deposition we observed in response to IUV.
We have previously shown that $\alpha$ SMA staining in the distal lung parenchyma, increases within 1-6 h of IUV onset and persists for up to $7 \mathrm{~d}$ after IUV ceases (18). Thus, increased $\alpha$ SMA expression occurs early in the process of myofibroblast differentiation and the induced phenotypic changes are not readily reversible. In this study, we found that increased $\alpha$ SMA staining is oxygen dependent and increases with increasing dose but with no increase in fetuses exposed to $100 \%$ nitrogen. Although hyperoxia has been shown to induce myofibroblast differentiation, this is the first study to demonstrate that ventilation alone, without oxygen, does not cause persisting changes in myofibroblast differentiation. Furthermore, as IUV without oxygen reduces secondary septal crest densities without increasing $\alpha$ SMA staining, it seems that ventilation alone can disrupt alveolarization without increasing myofibroblast differentiation.

Ventilation with oxygen increased cellular apoptosis in the distal lung parenchyma, with increased staining apparent in interstitial cell populations. Increased apoptosis did not occur in the absence of oxygen suggesting that apoptosis in the distal lung is oxygen dependent. Apoptosis remains significantly elevated at least $7 \mathrm{~d}$ after IUV ceases and occurs equally in response to $21 \%$ versus $100 \%$ oxygen. Combined with the potential for a marked increase in cell proliferation (18), increased apoptosis could lead to marked changes in the numerical distribution of cell populations in the distal lung parenchyma, thereby contributing to abnormal development associated with IUV.

Chronic hyperoxia increases collagen deposition in spontaneously breathing neonatal mice (8), and mechanical ventilation of the immature lung is known to increase and alter the spatial pattern of collagen deposition $(18,27,31)$. The effect of mechanical ventilation on collagen deposition is thought to be via a direct effect of mechanical strain on epithelial cells which signal interstitial fibroblasts to increase collagen production in vitro (32). Interestingly, ventilation with $100 \%$ nitrogen significantly decreased collagen levels within lung parenchyma. Although the mechanisms responsible for this decrease remain unknown, this suggests that ventilation alone causes an imbalance in pulmonary collagen metabolism, resulting in a net loss of collagen.

The relative contributions of oxygen and ventilation per se to VILI and the abnormal changes in lung structure are largely unknown, although this study shows both have separate contributing roles. In the absence of oxygen, ventilation of the immature lung during the canalicular stage of lung development, results in substantial changes in distal lung structure, suggesting that the mechanical effect of ventilation is sufficient to disrupt alveolar development. On the other hand, acute exposure to oxygen $(6 \mathrm{~h})$, even just air, increases distal lung tissue volumes, elastin deposition, myofibroblast differentiation, and apoptosis. Further studies are needed to quantify the timing and duration of ventilation and oxygen exposure in the immature lung that cause these changes.

Acknowledgments. We are indebted to Ms. Alison Moxham, Ms. Valerie Zahra, Mr. Alex Satragno, and Ms. Malgor- 
zata Zieba for their expert technical assistance and Dr. Tim Moss for his help in preparing the manuscript.

\section{REFERENCES}

1. Rickett GM, Kelly FJ 1990 Developmental expression of antioxidant enzymes in guinea-pig lung and liver. Development 108:331-336

2. Davis JM, Dickerson B, Metlay L, Penney DP 1991 Differential-effects of oxygen and barotrauma on lung injury in the neonatal piglet. Pediatr Pulmonol 10:157-163

3. Coalson JJ, Winter VT, Siler-Khodr T, Yoder BA 1999 Neonatal chronic lung disease in extremely immature baboons. Am J Respir Crit Care Med 160:1333-1346

4. Saugstad OD 2003 Bronchopulmonary dysplasia-oxidative stress and antioxidants. Semin Neonatol 8:39-49

5. Bonikos DS, Bensch KG, Northway WH, Edwards DK 1976 Bronchopulmonary dysplasia - pulmonary pathologic sequel of necrotizing bronchiolitis and pulmonary fibrosis. Hum Pathol 7:643-666

6. Jobe AJ 1999 The new BPD: an arrest of lung development. Pediatr Res 46:641-643

7. Rojas MA, Gonzalez A, Bancalari E, Claure N, Poole C, Silva-Neto G 1995 Changing trends in the epidemiology and pathogenesis of neonatal chronic lung disease. J Pediatr 126:605-610

8. Warner BB, Stuart LA, Papes RA, Wispe JR 1998 Functional and pathological effects of prolonged hyperoxia in neonatal mice. Am J Physiol 275:L110-L117

9. Randell SH, Mercer RR, Young SL 1990 Neonatal hyperoxia alters the pulmonary alveolar and capillary structure of 40-day-old rats. Am J Pathol 136:1259-1266

10. Yi M, Jankov RP, Belcastro R, Humes D, Copland I, Shek S, Sweezey NB, Post M, Albertine KH, Auten RL, Tanswell AK 2004 Opposing effects of $60 \%$ oxygen and neutrophil influx on alveologenesis in the neonatal rat. Am J Respir Crit Care Med 170:1188-1196

11. Nadeau K, Jankov RP, Tanswell AK, Sweezey NB, Kaplan F 2006 Lgl1 is suppressed in oxygen toxicity animal models of bronchopulmonary dysplasia and normalizes during recovery in air. Pediatr Res 59:389-395

12. Chang LY, Subramaniam M, Yoder BA, Day BJ, Ellison MC, Sunday ME, Crapo JD 2003 A catalytic antioxidant attenuates alveolar structural remodeling in bronchopulmonary dysplasia. Am J Respir Crit Care Med 167:57-64

13. Maniscalco WM, Watkins RH, Pryhuber GS, Bhatt A, Shea C, Huyck H 2002 Angiogenic factors and alveolar vasculature: development and alterations by injury in very premature baboons. Am J Physiol Lung Cell Mol Physiol 282:L811-L823

14. Belik J, Jankov RP, Pan J, Tanswell AK 2003 Chronic $\mathrm{O}_{2}$ exposure enhances vascular and airway smooth muscle contraction in the newborn but not adult rat. J Appl Physiol 94:2303-2312

15. Slutsky AS 1999 Lung injury caused by mechanical ventilation. Chest 116:9S-15S

16. Ricard JD, Dreyfuss D, Saumon G 2003 Ventilator-induced lung injury. Eur Respir J Suppl 42:2s-9s

17. D'Angio CT, Finkelstein JN, Lomonaco MB, Paxhia A, Wright SA, Baggs RB, Notter RH, Ryan RM 1997 Changes in surfactant protein gene expression in a neonatal rabbit model of hyperoxia-induced fibrosis. Am J Physiol 272:L720-L730

18. Allison BJ, Crossley KJ, Flecknoe SJ, Davis PG, Morley CJ, Harding R, Hooper SB 2008 Ventilation of the very immature lung in utero induces injury and BPD-like changes in lung structure in fetal sheep. Pediatr Res 64:387-392
19. Nardo L, Maritz G, Harding R, Hooper SB 2000 Changes in lung structure and cellular division induced by tracheal obstruction in fetal sheep. Exp Lung Res 26:105-119

20. Weibel ER, Gomez DM 1962 A principle for counting tissue structures on random sections. J Appl Physiol 17:343-348

21. Albertine KH, Jones GP, Starcher BC, Bohnsack JF, Davis PL, Cho SC, Carlton DP, Bland RD 1999 Chronic lung injury in preterm lambs. Disordered respiratory tract development. Am J Respir Crit Care Med 159:945-958

22. Ozer EA, Kumral A, Ozer E, Duman N, Yilmaz O, Ozkal S, Ozkan H 2005 Effect of retinoic acid on oxygen-induced lung injury in the newborn rat. Pediatr Pulmonol 39:35-40

23. Veness-Meehan KA, Bottone FG, Stiles AD 2000 Effects of retinoic acid on airspace development and lung collagen in hyperoxia-exposed newborn rats. Pediatr Res 48:434-444

24. Jankov RP, Johnstone L, Luo X, Robinson BH, Tanswell AK 2003 Macrophages as a major source of oxygen radicals in the hyperoxic newborn rat lung. Free Radic Biol Med 35:200-209

25. Dauger S, Ferkdadji L, Saumon G, Vardon G, Peuchmaur M, Gaultier C, Allego J 2003 Neonatal exposure to $65 \%$ oxygen durably impairs lung architecture and breathing pattern in adult mice. Chest 123:530-538

26. Bland RD, Xu L, Ertsey R, Rabinovitch M, Albertine KH, Wynn KA, Kumar VH, Ryan RM, Swartz DD, Csiszar K, Fong KS 2007 Dysregulation of pulmonary elastin synthesis and assembly in preterm lambs with chronic lung disease. Am J Physiol Lung Cell Mol Physiol 292:L1370-L1384

27. Pierce RA, Albertine KH, Starcher BC, Bohnsack JF, Carlton DP, Bland RD 1997 Chronic lung injury in preterm lambs: disordered pulmonary elastin deposition. Am J Physiol 272:L452-L460

28. Veness-Meehan KA, Pierce RA, Moats-Staats BM, Stiles AD 2002 Retinoic acid attenuates $\mathrm{O}_{2}$-induced inhibition of lung septation. Am J Physiol Lung Cell Mol Physiol 283:L971-L980

29. Bruce MC, Bruce EN, Janiga K, Chetty A 1993 Hyperoxic exposure of developing rat lung decreases tropoelastin messenger-RNA levels that rebound postexposure. Am J Physiol 265:L293-L300

30. Rehan V, Torday J 2003 Hyperoxia augments pulmonary lipofibroblast-tomyofibroblast transdifferentiation. Cell Biochem Biophys 38:239-250

31. Thibeault DW, Mabry S, Ekekezie II, Zhang X, Truog WE 2003 Collagen scaffolding during development and its deformation with chronic lung disease. Pediatrics 111:766-776

32. Swartz MA, Tschumperlin DJ, Kamm RD, Drazen JM 2001 Mechanical stress is communicated between different cell types to elicit matrix remodeling. Proc Natl Acad Sci USA 98:6180-6185

33. McAnulty RJ 2007 Fibroblasts and myofibroblasts: their source, function and role in disease. Int J Biochem Cell Biol 39:666-671

34. Kim N, Vu TH 2006 Parabronchial smooth muscle cells and alveolar myofibroblasts in lung development. Birth Defects Res C Embryo Today 78:80-89

35. Serini G, Gabbiani G 1999 Mechanisms of myofibroblast activity and phenotypic modulation. Exp Cell Res 250:273-283

36. Boros LG, Torday JS, Lee WN, Rehan VK 2002 Oxygen-induced metabolic changes and transdifferentiation in immature fetal rat lung lipofibroblasts. Mol Genet Metab $77: 230-236$ 